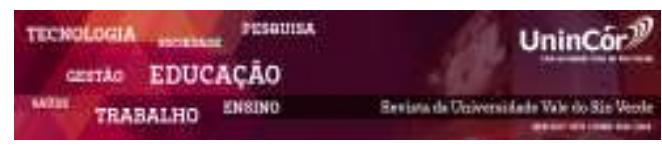

Revista da Universidade Vale do Rio Verde ISSN: 1517-0276 / EISSN: 2236-5362 Vol. 16 | n. 1 | Ano 2018

Bruno Gadelha Xavier Universidade Federal do Rio de Janeiro (UFRJ) brunogadelhaxavier@hotmail.com

\section{A PERFOMANCE RETÓRICA DE NIETZSCHE: A IMPORTÂNCIA DA RETÓRICA NO ESTUDO DE SUA FILOSOFIA}

\begin{abstract}
RESUMO
$\mathrm{O}$ presente artigo busca discutir uma relevante passagem da filosofia de Nietzsche, qual seja, seus cursos sobre Retórica. Discutirse-á premissas como a função da linguagem, desde a percepção do auditório, a fim de elencar o caráter performático de seu pensamento, inserido na presença de verbos na primeira pessoa do singular como forma performática na "guerra" contra o cristianismo, sendo caráter marcante de sua escrita, indicando personalização e individualização. Desta feita, o artigo almeja uma contribuição coerente na difícil tarefa de interpretar a obra do autor a partir do reconhecimento da existência de verbos performativos, a partir de uma metódica voltada ao close reading das obras selecionadas.
\end{abstract}

Palavras-chave: Caráter Performático. Cursos de Retórica. Linguagem. Personalização. Nietzsche.

\section{NIETZSCHE'S RHETORICAL PERFORMANCE: THE IMPORTANCE OF RHETORIC ON THE STUDY OF HIS PHILOSOPHY}

\begin{abstract}
The paper seeks to discuss a relevant passage of Nietzsche's philosophy, that is, his courses on Rhetoric. We will discuss assumptions as the function of language, from the perception of the audience, in order to list the performative character of their thinking, inserted in the presence of verbs in the first person singular as a performance form in the "war" against Christianity, being a marked character of his writing, indicating personalization and individualization. This article aims at a coherent contribution to the difficult task of interpreting the author 's work from the recognition of the existence of performative verbs, based on a methodical approach to the close reading of the selected works.
\end{abstract}

Keywords: Performative character. Rhetoric courses. Language. Personalization. Nietzsche. 


\section{INTRODUÇÂO}

Dos possíveis textos que um filósofo pode escolher para intentar uma investigação e explorar os meandros hermenêuticos da potencialidade do escrito, os aforismos de Nietzsche permanecem como uma forma de expressão única. Não somente por um afastamento da tradição metafísica, mas pela consequência prática e crítica que sua leitura proporciona.

Ao certo, Nietzsche é uma personalidade que obriga seus leitores a tomarem decisões últimas, uma vez os caminhos errados que o homem havia tomado, que concretizou o que se conhece como santo, bom e verdadeiro. Desta feita, o filósofo encarna a crítica mais extrema da religião, da filosofia e da ciência, bem como da moral, conferindo repulsa às tradições, e convidando a uma radical volta para o passado ${ }^{1}$.

O filósofo, como observa Fink (2000, p.9-10), sempre esteve oculto e dissimulado pelo crítico da cultura, pelo algoz misterioso, ou pelo profeta eloquente. A essência dessa filosofia está por trás das máscaras, da performatividade de quem denomina gênio. Segue-se a afirmação de Gilles Deleuze, quando este menciona que a aurora da atual cultura moderna encontra-se na trindade Nietzsche, Freud e Marx, com o primei-

\footnotetext{
1 "Nietzsche lucha con una entrega total, pero no realiza una destrucción conceptual de la metafísica, no la desmonta con los mismos medios del pensar conceptual del ser, sino que repudia el concepto, lucha contra el racionalismo, se opone a la violación de la realidad por el pensamiento. Su discusión con el pasado la realiza Nietzsche en un amplio frente. No polemiza sólo contra la moral y la religión tradicionales. Su lucha tiene Já forma de una crítica total de la cultura. Este factor es de gran importância." (FINK, Eugen. La filosofía de Nietzsche. Madrid: Alianza Editorial, 2000, p.9-10).
}

ro representando mais uma forma de contracultura (DELEUZE, 1985, p.57).

$\mathrm{O}$ presente artigo, portanto, tem como objetivo explicitar uma de suas mais valiosas passagens, qual seja, os "cursos de retórica", no tocante ao caráter performativo que sua retórica possui. Todavia, não é pretensão do presente esgotar o tema, apenas conferir uma base introdutória concreta em torno do trabalho de Nietzsche em torno de um dos possíveis aspectos filosóficos.

A tarefa do intérprete de Nietzsche é, não somente difícil, mas eloquente. Seus aforismos $^{2}$ constantemente embriagadas com

${ }^{2}$ Calha mencionar que a própria estrutura de escrita a partir de aforismos é um ato dotado de performatividade invejável, todavia, fica a sustentação de Jill Marsden como ressalva: "The first of Nietzsche's texts to make extensive use of the aphoristic form is Human, All Too Human (1878), which interweaves a variety of acerbic, incisive and observational maxims with short paragraph essays of varying length. In its orthodox usage, the term "aphorism" is used to denote a short expression of a general truth or pointed assertion. Strictly speaking, the German word Sentenz (translated as "maxim" or "apophthegm") conveys this sense most closely, although Nietzsche often uses the term Aphorismus synonymously. His description of Human, All Too Human as a "collection of aphorisms" in the preface to On the Genealogy of Morals suggests that there may be some justification for taking the term "aphorism" to denote a style of writing rather than the classically terse statement; nevertheless, caution is required here. While it seems reasonable to regard some of the longer passages in Nietzsche's works as aphoristic in character (owing to their semantic and stylistic concision and their sharpness of observation) Nietzsche alludes to them simply as "sections" when making retrospective reference to such texts (for example in the preface to On the Genealogy of Morals and in Ecce Homo). For this reason, although it has become standard practice in Nietzsche scholarship to use the term "aphorism" to describe the vast majority of such numbered pieces, it is unwise to treat all examples of the latter as aphorisms, particularly in essay-length texts such as On the Genealogy of Morals, The Wagner Case, and Ecce Homo, where it would seem more accurate to describe them as chapters. Although it cannot settle the matter 
ácidas críticas ao comportamento filosófico metafísico trazem uma validade discursiva que transpõe o leitor para situações de estranhamento e espanto, que logo resultam em uma admiração nata a sua obra.

Com os textos escolhidos não é distinto. A preocupação em torno de uma análise prática em torno da performatividade - dentre outras temáticas -, ecoa demandas interpretativas e um debruçar acadêmico que colocam o leitor em uma posição de constante descoberta, de sentidos e elementos escusos na literalidade do escrito.

Tendo em observância o prisma supraestabelecido, calha apontar o desenvolvimento do presente artigo. No primeiro tópico a ser abordado, busca-se uma conceituação básica da retórica no pensamento de Nietzsche, a partir da descrição do contato do filósofo com a temática em si.

Em um segundo momento, objetiva-se apresentar relevância do estudo da retórica em Nietzsche, em especial o modo pelo qual o autor, na aproximação ao estudo antigo, remonta em seus cursos sobre retórica a necessidade de se repensar a função da linguagem frente um auditório a ser persuadido.

Por conseguinte, no terceiro tópico, haverá a defesa da hipótese performática em Nietzsche, com consequente exemplo inserido no estudo sobre a presença de verbos na primeira pessoa do singular como forma performática na "guerra" contra o cristianismo.

decisively, reflection on what makes something "aphoristic" for Nietzsche is of obvious benefit to our inquiry." (MARSDEN, Jill. Nietzsche and the art of the Aphorism. In: PEARSON, Keith Ansell (org). The Backwell companion to Nietzsche. Blackwell: Oxford, 2006.)
Assim, o presente escrito objetiva proporcionar um complemento em torno da questão acima dissertada, jamais pretendendo esgotar a temática, mas oferecer certas pontuações em torno da proposta estabelecida.

\section{NIETZSCHE E A RETÓRICA: UMA RELAÇÃO DE COMPLEMENTAÇÃO NECESSÁRIA?}

De acordo com Manuel Barrios Casares, foram filósofos franceses como Michel Foucault e Jacques Derrida quem souberam demonstrar a relevância da reflexão nietzschiana sobre a linguagem no conjunto de sua produção filosófica. Todavia, em especial, a partir da década de setenta, em certa medida no encadeamento da denominada "virada lingüística", que a investigação própria sobre Nietzsche começou a mostrar de maneira crescente um interesse singular por sua tese acerca da íntima imbricação entre a palavra e pensamento (CASARES, 2012, p.7); por sua vez Lacoue-Labarthe (1971, p.100 e ss.) vê a aproximação de Nietzsche da Retórica uma forma para extinguir os pressupostos de sua, até então, teoria romântica da arte. Complementa o autor ao afirmar que:

Hoje, em meio a um clima mais consolidado de reabilitação do papel da retórica no discurso filosófico, esta via de aproximação da obra de Nietzsche oferece perspectivas inspiradoras e renovadoras de leitura, que incitam a aprofundar tanto o conhecimento histórico- filológico dos 
escritos nietzschianos dedicados a tal temática quanto o debate filosófico sobre sua significação e alcance.

Ao certo, pode-se afirmar que, na análise de uma possível história da filosofia, Nietzsche foi um dos filósofos da modernidade responsáveis pela reabilitação da retórica, relacionando esta à linguagem e pensamento. Afinal, a partir da tragédia ou do diálogo com figuras clássicas do campo filosófico, o autor determinou uma visão de filosofia sustentada por uma original aproximação da retórica. $\mathrm{O}$ que se observa do seu colendo de escritos é uma hermenêutica possível de símbolos, signos e imagens, que fazem um grande jogo, um giro "retórico" de Nietzsche que demonstra um modo próprio de filosofar.

Sustenta Rosana Suarez (2000, p.68) que dois primas parecem convergir quanto ao interesse do filósofo em comento pela retórica. Não obstante as leituras de Die Rethorik der Griechen und Römer in systematischen übersicht, de Richard Wolkmann, e Der sprache als Kunst, de Richard Gerber, as preocupações com o sustentáculo do estilo, da forma de linguagem, que já se encontram em "Sobre o futuro de nossos estabelecimentos de ensino" (1872) (SUAREZ, 2000, p.68). Como segundo prisma, tem-se a preocupação da retórica se exercitar sobretudo no discurso oral, contrariando corroborando a valorização dos aspectos da emissão e da sonoridade da linguagem, inseridos em "O nascimento da tragédia", quando do sublinhar de carga emotiva superior, realçando o que havia na linguagem de musicalidade.
Suarez desenvolve seu raciocínio complementando o supramencionado no momento em que sustenta que a concepção acima disposta associa a metafísica da tragédia, uma vez que esta seria via de regra o opus metaphysicum, uma vez a presença dos artifícios da ilusão, da aparência, submetidos ao imperativo da necessidade de expressão do ser uno originário - coro trágico, dionisíaco. Auscultando a esfera musical da tragédia encontra-se, perdido nas aparências artísticas, a linguagem afetiva (SUAREZ, 2000, p.68).

Interessante apontar que nos escritos sobre a tragédia a musicalidade se apresenta como a dimensão mais relevante da linguagem, com a música como núcleo metafísico da tragédia, com linguagem universal acessível a todos (SUAREZ, 2000, p.68).

Por sua vez, no curso "Retórica" (NIETZSCHE, 2000, Retórica (R), p.111), afirmou que o desenvolvimento do senso rítmico entre gregos e romanos foi extraordinário, e para quem escutar a palavra se fazia momento de um formidável e contínuo exercício, uma arte destinada antes de tudo ao ouvido, com o intuito de seduzi-lo. Assim, para o filósofo, toda a arte comporta um grau de retórica, entre os gregos ars, téchne, designa a técnica retórica de um povo de artistas, reconhecendo que visa enganar.

Mais uma vez Suarez apresenta tese a ser elucidada. Embora não mencione o nome de Apolo e Dionísio, Nietzsche privilegia o aspecto encobridor e dissimulador de Apolo - deus da aparência, ilusão - sobre a fala musical de Dionísio (Retórica (R), p.69). 
Após este breve sustentáculo introdutório, passase a importância da linguagem e sua relação com a retórica nos escritos de Nietzsche.

\section{A LINGUAGEM COMO ELEMENTO CONSTITUTIVO DA FILOSOFIA DE NIETZSCHE: IMPACTOS RETÓRICOS}

O interesse do filósofo na questão da linguagem traz a necessidade de um olhar para os anos de 1868. Manifestado inicialmente em considerações esparsas, que acabaram antecipando suas ideias sobre o caráter figurativo da linguagem, e, posteriormente, em fragmentos mais concisos de redação, como a introdução ao curso de gramática latina de 1869/70 - Vom Ursprung der Sprache ${ }^{3}$.

A tese básica elucidada no "Curso de Retórica" pela qual os tropos não são considerados um acréscimo à linguagem, mas sua natureza íntima, e, por decorrência lógica, a retórica não se caracteriza como nada mais do que artifícios já presentes na linguagem, induz a uma contraposição ao intento metafísico de um dizer epistemológico que esteja destituído da persuasão inerente à dóxa:

\footnotetext{
"Dado que esta crítica à pretensão fundamentadora da metafísica não desemboca na mera substituição da epistême de um mundo verdadeiro
}

\footnotetext{
3 "E, como mostrou Claudia Crawford em seu estudo sobre os inícios da teoria nietzschiana da linguagem, $A$ filosofia do inconsciente (Berlim, 1869) de Eduard von Hartmann representa, aqui, a principal fonte de inspiração das teses do jovem Nietzsche sobre a impossibilidade de se pensar à margem da linguagem e a sua condição de produto do instinto." (CASARES, Manuel Barrios. O "giro retórico" de Nietzsche. In: Cadernos Nietzsche. Vol.13. São Paulo: 2012, p.11).
}

pela fábula de um mundo aparente, mas, antes de tudo, no problema de sua indistinção, cabe supor que o progressivo desinteresse de Nietzsche pela retórica como disciplina obedece ao fato de que esta não representa, em definitivo, mais que um caso particular e derivado da artística potência figurativa implícita em toda linguagem. Nietzsche concentra, assim, seu interesse na dimensão da linguagem como uma "arte inconsciente", informado do sentido tão limitado em que se deve conceber a retórica como algo a mais do que uma arte do ornamento discursivo e que, certamente, ele criticou desde as primeiras seções do Curso. É provável também que o desuso de uma terminologia que remeta ao terreno da retórica deva-se, afinal de contas, ao fato de que sua atenção ao problema da origem e da função da linguagem tenha sido suscitada como uma questão induzida a partir de preocupações preferencialmente

gnosiológicas e, em última instância, da crítica da metafísica e da crítica da cultura." (CASARES, Manuel Barrios. O "giro retórico" de Nietzsche. In: Cadernos Nietzsche. Vol.13. São Paulo: 2012, p.13-14)

Conforme já dito, ao delimitar o núcleo retórico a ser trabalhado, Nietzsche privilegia a trópica, ou seja, as designações impróprias, retomando o clássico vocabulário da oratória, que opõe o tropo à palavra própria (2000, Retórica (R), p.112-115). A retórica se propõe a 
substituir este significar próprio, como recurso estilístico performático, por uma significação figurada, artificialmente tomando a expressão original.

Exemplifica o filósofo ao mencionar a substituição do termo barco por vela. O termo próprio "barco" é trocado por outro que traz consigo aspectos meramente designativos, todavia, o que nele mais se observa é a vela. Este deslocamento, que detém o comando de coimplicação, e consequente transposição do sentido de um todo para uma parte é denominado sinédoque.

Ademais, a metáfora também encontrase em uma transposição de significação, a partir de uma comparação abreviada. Assim sendo, complementa Suarez (2000, p.70):

A metáfora também nasce de uma "transposição de significação". Nesse caso, a transposição seria comandada por uma "comparação abreviada", frequentemente elíptica. Por exemplo, falamos em pés e flancos em relação à montanha, comprando a conformação geológica à anatomia humana, cujas relações de distância e posição transportamos para o outro contexto. Nietzsche lembra que na antiguidade, mais do que uma figura em particular, a metáfora designa pura $\mathrm{e}$ simplesmente a transposição, lei geral da trópica, chegando a confundir-se com ela; nesse sentido, a metáfora é tropo por excelência.

Insta indicar que, no exercício da performática persuasiva inserida no discurso de Nietzsche, a utilização da linguagem própria, que possui a palavra de significação precisa, sancionada, é regida pela clareza e pela conveniência. É acentuado a clareza pelo uso das imagens e comparações, outrossim, pelos recursos expressivos e de amplificação. Não obstante, também se torna relevante a presença de figuras e artifícios para maior conveniência.

Desta forma, a partir do exposto, deve-se mencionar que o discurso de forma conveniente é visto pelo filósofo como uma adoção da aparência de sinceridade pela "naturalidade" vista na retórica, uma imitação da natureza. Assim, na boca de quem fala o discurso deve almejar parecer uma conveniência e algo natural, dissimulando a arte da substituição, sob pena de se resultar em um auditório desconfiado e temente à enganação. Quando quem fala possui uma linguagem adequada, o auditório crê na seriedade e na verdade defendida na causa postulada, se comovendo com o orador, que vira uma espécie de ser a ser creditado, e, por consequência, alguém sincero (NIETZSCHE, 2000, Retórica (R), p.117).

Por fim, apenas por fins de complementação do presente escrito, vale destacar que o discurso persuasivo, feito perante os ditames da naturalidade, os cuidados da dissimulação, e os recursos do artifício resultam em uma combinação de conflito - dominação - e aspectos lúdicos - arte, beleza - que condizem com a antiga tendência agonal.

De acordo com Nietzsche, a partir desta tendência, toda a produção individual em público é uma competição, todavia, para o combatente, apenas possuir robustas armas não é o suficiente, é necessário que elas também sejam brilhantes. Ademais, não é suficiente que elas sejam 
convenientes, também devem ser belas, para que não somente o combatente vença, mas que saia vitorioso com elegância. O agonal, portanto, exige não apenas a impressão de sinceridade, mas também a superioridade, dignidade, beleza e liberdade na forma combativa (2000, Retórica (R), p.118).

Por fim, Suarez afirma que esta tendência agonal, na qual o impróprio se converte em próprio por um conjunto de artistas, concentrou paulatinamente o campo global da linguagem, outrossim, da cultura grega antiga, uma marca distintiva (SUAREZ, 2000, p.73).

Após o supramencionado, passa-se a defesa da performatividade inserida na visão da retórica de Nietzsche.

\section{NIETZSCHE， PERFORMATIVIDADE E RETÓRICA: A LINGUAGEM PERFORMATIVA}

De acordo com Linda Simonis, a partir da verificação de certos aforismos de Nietzsche, é possível verificar a compreensão da linguagem enquanto ação no mundo, principalmente quanto a questão da sedução que possui o discurso, um efeito adjetivado ao certo como epidítico ao instrumentalizar uma retórica material e alterar a opinião dos indivíduos. Assim, a autora sustenta ser o filósofo um defensor do performativo avant-la-letre (SIMONIS, 2002, p.58).

A partir da hipótese acima destacada, passa-se ao sustentar da existência de elementos performativos no discurso de Nietzsche, em especial pela sua visão e uso da retórica em si, demonstrando a importância da análise e da defesa da potencialidade da linguagem em sua obra, além da perspicácia de um autor que compreendia a necessidade de relação que se deve manter com o leitor a ser persuadido e convencido.

Menciona Rodrigo Barbosa que Austin, no momento em que caracteriza o performativo da linguagem, destaca que uma dos adjetivos fundamentais dos verbos performáticos é a presença da primeira pessoa do singular. No momento em que se fixa a força enunciativa do uso da primeira pessoa nos aforismos do filósofo em comento, pode-se observar a complexidade que o elemento egocêntrico (eu) denuncia no que se refere ao intuito de performar atos, conferindo não apenas o efeito estético pretendido, bem como, conforme já mencionado, um efeito epidítico (BARBOSA, 2013, p.2).

De acordo com Barbosa, a performatividade nos textos de Nietzsche pode ser observada principalmente nos últimos textos de 1888 , como a presença de modulações da voz (BARBOSA, 2013, p.1). Em que pese o presente artigo não ter por objetivo específico esgotar hipóteses performativas - impossível não apenas para um artigo, mas para qualquer intérprete da filosofia de Nietzsche que procure indevidamente esgotar interpretações de suas obras - vale mencionar o exemplo da inserção da primeira pessoa do singular como uma forte característica do texto do filósofo como uma denúncia do vislumbrar da performatividade em discussão. Neste sentido, vale a citação de Barbosa (2013, p.7):

A primeira pessoa do singular é a característica mais forte do texto de Nietzsche com exceção 
apenas quando ele se utiliza da voz de outras personagens: como é o caso do próprio "Sr. Nietzsche" no prólogo da Gaia Ciência, da concessão a fala do martelo do Crepúsculo dos Ídolos [...], e as diversas

instrumentalizações que ele faz de variadas personagens. Este fato além de indicar uma forte personalização singularização do pensamento, implica como mencionado acima uma caracterização deste uso linguístico como pertencente aos "verbos performativos", apenas para vincular tal propriedade àquela primeira taxonomia de Austin.

Conforme já mencionado, a presença da singularização do pensamento e da personalização do mesmo denota a importância do filósofo no uso do discurso como forma de exercício de uma performatividade própria e persuasiva, direcionada ao leitor que observa a presença deste "eu", fixando a linguagem como uma atividade que cria efeitos concretos, dando forma, performando e transformando o mundo.

A presença do "eu" pode ser vista ainda nos enunciados de 1988, em especial os de declaração de guerra, como "eu declaro", "eu condeno", "eu levanto", "eu faço". Atenção deve ser dada ao combate ao cristianismo nestas passagens. Há uma forma de violência condenatória - "Lei contra o cristianismo", vide aforismo 62 de "O Anticristo" no qual ele "condena" e "faz" a terrível acusação. No aforismo nove, a presença do elemento "eu faço", como uma forma de batalha contra o instinto do teólogo. Corroborando o dito, Barbosa (2013, p.8) afirma:

Temos nestes dois usos uma variação sutil do verbo fazer: enquanto no uso final o "fazer" como realização de "ich erheben...” indica além do sentido físico de elevar, também os sentidos de "elogiar, declamar, pedir, começar", no verbo "machen" encontrado no aforismo 9 o sentido é mais obvio à realização que implica "fazer, efetuar". O que parece ser atribuído a esse uso sutil e esporádico dos dois verbos é o fato de que, no início do texto, o embate de Nietzsche contra o cristianismo e seus representantes é realizado enquanto consciência de um "fazer guerra", isto é, se reconhece desde então que se está fazendo naquele exato momento, guerra ao cristianismo, por isso o "a esse instinto de teólogo eu faço guerra”. Já em relação ao "fazer" de erheben do final de $\mathrm{O}$ Anticristo há uma série de conotações e outros verbos relacionados a uma ideia legisladora de "levantar, proclamar, declarar" como seria a efetivação de uma nova tábua de valores: é assim que, prestes a "inscrever em todos os muros essa perene acusação" e, gravá-la "signo por signo em tábuas de bronze" Nietzsche "pronuncia", "condena" e assim "faz" uma acusação a o cristianismo, ou seja, passa-se da mera fala (spreche) ao ato de condenação (verurtheile) que tem como efeito uma ação efetiva no mundo (erheben). 
Observa-se, assim, um exemplo no qual a percepção performativa da linguagem na obra de Nietzsche, vista na figura de um "eu”, ganha força de combate contra o cristianismo, uma intenção performática na qual se denuncia a guerra travada pelo filósofo na transvaloração valorativa a ser perpetuada em seus escritos. Daí a visível importância do estudo da retórica perpetuada pelo autor, no momento em que a linguagem se torna arma performática nas trincheiras do combate crítico às tradições cristãs.

\section{APORTES CONCLUSIVOS}

Nietzsche nunca esteve tão atual. Com o fim do século XX, restou claro em termos de campo filosófico que inúmeras de suas denúncias e críticas em relação ao comportamento ocidental estavam e continuam precisas. Seus escritos obtiveram influência inigualável não apenas quanto à ruptura no próprio pensamento filosófico, como em outros núcleos, trazendo uma nova e performática forma de se pensar os enigmas da vida.

O presente trabalho procura concluir em que pese saber da infelicidade do emprego do termo conclusão para trabalhos acadêmicos que detém como base uma obra de Nietzsche - a sua tentativa de elucidação acerca do tema a performatividade nos aforismos e a relevância da retórica.

Assim sendo, conforme já dito, a presença do performativo da linguagem é exemplificada pela presença de verbos performáticos na primeira pessoa do singular, algo visto nos escritos de 1988. A relevância do estudo da linguagem e da percepção da persuasão e do auditório tornam o texto de Nietzsche um campo de batalha único na crítica perpetuada pelo autor.

De certo, a reflexão é apenas o início de uma discussão muito maior, entretanto, uma manobra vestibular é necessária para o elucidar de conceitos em torno do debate inserido, demonstrando a marca de singularidade e individualidade na retórica do autor. O recorte temático apresentado no presente artigo apenas reforça a posição da importância da filosofia em tela, posto a multiplicidade de leitores tão diversos, em situações tão plúrimas. Uma das possíveis temáticas na obra que ecoa em inúmeras vertentes e proporciona uma lógica reflexiva própria.

\section{REFERÊNCIAS}

BARBOSA, Rodrigo Francisco. Nietzsche e a linguagem performativa: performativos explícitos e a fala do martelo. In: Trágica: estudos sobre Nietzsche. Vol.6. n.1. jan/jul. 2013, p.1-13.

CASARES, Manuel Barrios. O "giro retórico" de Nietzsche. In: Cadernos Nietzsche. Vol.13. São Paulo: 2012.

DELEUZE, Gilles. Pensamento nômade. In: MARTON, Scarlett(org.).Nietzsche hoje? Colóquio de Cerisy. São Paulo: Brasiliense, 1985.

FINK, Eugen. La filosofía de Nietzsche. Madrid: Alianza Editorial, 2000.

LACOUE-LABARTHE, P.; NANCY, J.L. Nancy (eds.). "Friedrich Nietzsche. Rhétorique et langage". In: Poétique, II, 1971, pp. 99-143.

MARSDEN, Jill. Nietzsche and the art of the Aphorism. In: PEARSON, Keith Ansell (org). The 
Backwell companion to Nietzsche. Blackwell: Oxford, 2006.

NIETZSCHE, Friedrich. Escritos sobre retórica. Madri, Trotta, 2000.

SIMONIS, Linda. Der Stil als Verführer: Nietzsche und die Sprache des Performativen. In: NietzscheStudien. Band 31, 2002. Disponível em: http://10.1515/9783110170740.57. p.57-74.

SUAREZ, Rosana. Nietzsche e os cursos sobre a retórica. In: $O$ que nos faz pensar. n.14. Agosto de 2000 .

\section{Bruno Gadelha Xavier}

Doutorando em Filosofia pela Universidade Federal do Rio de Janeiro (UFRJ). Doutorando em Educação pela Universidade Federal do Espírito Santo (UFES); Mestre e Doutorando em Direitos e Garantias Fundamentais pela Faculdade de Direito de Vitória (FDV); Mestre em Filosofia pela Universidade Federal do Espírito Santo (UFES); Pós-Graduado em Direito Processual Civil pela Faculdade de Direito de Vitória (FDV); Bacharel em Direito pela Faculdade de Direito de Vitória (FDV); Membro do Grupo de Pesquisa "Direito, Sociedade e Cultura" (FDV), do NEPEFIL - Núcleo de Estudos e Pesquisa em Educação e Filosofia (UFES), e do Grupo de Pesquisa Pensamento e Linguagem (UFES). Professor Universitário. 